Editorial

\section{Dear author, what is your name?}

\author{
Prezado autor, qual é o seu nome?
}

Fernando Fernandez-Llimos

Doi: $10.30968 /$ rbfhss.2019.102.0416

Although we all live in a 'publish or perish' world, we should keep in mind that the main purpose of an article is to slightly increase the cumulative knowledge by adding a small piece of innovation to the myriad of previously published articles. In fact, the word myriad [NB: ten thousand in ancient Greek] is insufficient to describe the amount of articles published yearly. PubMed is indexing more than a million biomedical articles per year. This means that writing the paper is the easy part of the game; making the paper visible to the scientific community is a bit more complicate.

Too frequently, authors write their papers more for themselves than for the rest of the world. Strange titles, useless abstracts, complex terminology, and an abusive use of odd abbreviations, convert the text in a cryptogram that no one else that the authors and a restrict number of acquaintances can understand. And more important, these bad writing practices hamper the identification and the access to good and relevant pieces of research that may remain ignored just because we are not careful with the good scientific writing practices.

Among all the information contained in an article metadata, one could think that authors are highly interested in being clearly identified and recognized as part of the team that wrote that paper. So, journal editors put authors' names in the very first page of each article. But, why is this necessary? Every group of authors knows that they wrote that paper, so the aim of including the names on the first page is letting others know that these authors wrote the paper. In fact, apart from curriculum purposes, having the name on the first page is part of the "esteem needs" that Abraham Maslow described in his motivation theory as previous stage to the "self-actualization" (i.e. achieving one's full potential). Yes, we write our names in the first page to fulfill our egos. We could anonymously add that small piece of innovation to the myriad of previously published articles, but we do not want to.

Surprisingly, authors write frequently their names as a cryptogram. When I sit for the first time with a Masters or a PhD student, we have a one hour conversation about general topics that will be relevant for the following two or four years that we are going to share. I explain them that they will necessarily become advanced users of three software tools, Excel, EndNote, and SPSS. And then I surprise them with the sentence: "now, let's set what's your name". They look at me and they often doubt if they have chosen the right supervisor, because they are sure they know their names. Then, they speak their name and we start a discussion to convert their typical Brazilian or Portuguese names into an internationally sound name.

Constitution of a name varies in different regions of the world. Portuguese and Brazilian names are usually constituted by a given name, frequently with more than one word, and then a series of family names, with the last one as predominant. Hispanic names are also constituted by a given name, also frequently comprising more than one word, and a list of family names, but with the first one as predominant. Indian names usually have a given name written in full, and only the initial of the last name. American names have almost always a Given name, the initial of a middle name, and a last name, while British of Australians usually ignore their middle name. To complicate even more this variety of geographical rules, women in many countries change their last name when get married, sometimes using their husband's last name, and sometimes adding husband's last name to their single last name with a hyphen in between.

An article author does not need a stage name, like singers or movie stars. We need an 'indexable name', As we write the name in the first page of the articles to let the others know that we wrote that paper, we should also consider that articles are indexed in bibliographic databases that allow other researchers and practitioners find our article, and subsequently our name in that record. This means that authors should use a name that fits in the international indexing rules. These rules are very simple, and based in three fields:

$$
\begin{aligned}
& \text { - a given name } \\
& \text { - a middle initial } \\
& \text { - a last name }
\end{aligned}
$$

Brazilian Journal of Hospital Pharmacy and Health Services Revista Brasileira de Farmácia Hospitalar e Serviços de Saúde

Open access: http://www.rbfhss.org.br

Editors-in-Chief

\section{Angelita Cristine Melo}

Federal University of São João del Rei - Divinópolis, Brazil Elisangela da Costa Lima

Federal University of Rio de Janeiro, Rio de Janeiro, Brazil

\section{Associate Editors}

Fernando Fernandez Llimós

University of Lisbon, Lisbon, Portugal

Luciane Cruz Lopes

University of Sorocaba, Sorocaba, Brazil

Maria Rita Garbi Novaes

Health Sciences Education and Research Foundation, Brasilia, Brazil

Mario Jorge Sobreira da Silva

National Cancer Institute, Rio de Janeiro, Brazil

Renata Cristina Rezende Macedo do Nascimento

Federal University of Ouro Preto, Ouro Preto, Brazil

Vera Lucia Luiza

Oswaldo Cruz Foundation, Rio de Janeiro, Brazil

Editorial Board

Adriano Max Moreira Reis -Federal University of Minas Gerais, Belo Horizonte, Brazil

Ahmed Nadir Kheir - Qatar University, Doha, Qatar

Alberto Herreros de Tejada - Puerta de Hierro University Hospital, Majadahonda, Spain

Carine Raquel Blatt -Federal University of Health Sciences, Porto Alegre, Brazil Claudia Garcia Osorio de Castro - Oswaldo Cruz Foundation, Rio de Janeiro, Brazil

David Woods - University of Otago, Otago, New Zealand

Dayani Galato - University of Brasilia, Brasilia, Brazil

Divaldo Pereira Lyra Junior - Federal University of Sergipe, Aracaju, Brazil Eduardo Savio - Uruguayan Centre for Molecular Imaging, Montevideo, Uruguay

Inés Ruiz Álvarez - University of Chile, Santiago de Chile, Chile

João Carlos Canotilho Lage - University of Coimbra, Coimbra, Portugal Lúcia de Araújo Costa Beisl Noblat- Federal University of Bahia, Salvador, Brazil

Marcela Jirón Aliste - University of Chile, Santiago de Chile, Chile Marcelo Polacow Bisson- Military Police of São Paulo State, São Paulo, Brazil Maria Teresa Ferreira Herdeiro - University of Aveiro, Aveiro, Portugal Marta Maria de França Fonteles - Federal University of Fortaleza, Fortaleza, Brazil

Selma Rodrigues de Castilho - Fluminense Federal University, Rio de Janeiro, Brazil

Sonia Lucena Cipriano, University of São Paulo, São Paulo, Brazil

Editorial Design: Liana de Oliveira Costa Website support: Periódicos em Nuvens ISSN online: $2316-7750$

Mission

To publish and divulge scientific production on subjects of relevance to Hospital Pharmacy and other Health Services.

Publication of Hospital Pharmacy and Health Services Brazilian Society / Sociedade Brasileira de Farmácia Hospitalar e Serviços de Saúde

President - Maely Peçanha Favero Retto Vice-President - Valéria Santos Bezerra

Rua Vergueiro, 1855 - $12^{\circ}$ andar

Vila Mariana - São Paulo - SP, Brazil

CEP 04101-000 - Tel./Fax: (11) 5083-4297

atendimento@sbrafh.org.br/www.sbrafh.org.br 
What we put in each of these three fields will have consequences on how our name will be abbreviated when citing our article. Abbreviation process is automatically made by software and web applications by using the following rule: last name in full, plus only one initial of the given name, plus only one initial of the middle name. The names of the two editors in chief of the journal, Angelita Cristine de Melo and Elisangela da Costa Lima, are perfect to perceive the consequences of the different options they can choose (Table 1).

Table 1. Examples of names and citations.

\begin{tabular}{|c|c|c|c|c|}
\hline \multicolumn{3}{|c|}{ Author's choice } & \multicolumn{2}{|c|}{ Consequence } \\
\hline Given name & Middle name & Last name & Full name* & Abbreviation \\
\hline Angelita & Cristine & de Melo & Angelita Cristine DE MELO & De Melo AC \\
\hline Angelita & Cristine & Melo & Angelita Cristine MELO & Melo AC \\
\hline Angelita & & Cristine de Melo & Angelita CRISTINE DE MELO & Cristine de Melo A \\
\hline Elisangela & da Costa & Lima & Elisangela da Costa LIMA & Lima ED \\
\hline Elisangela & Costa & Lima & Elisangela Costa LIMA & Lima EC \\
\hline Elisangela & & da Costa Lima & Elisangela DA COSTA LIMA & Da Costa Lima E \\
\hline Elisangela & & Costa Lima & Elisangela COSTA LIMA & Costa Lima E \\
\hline
\end{tabular}

ISO:215 obliges to write last names in all-capital letters.

Authors are free to choose how they want to write their names, but they are prisoners of the consequences of their choices. 